\title{
Working Together Differently: Addressing the Housing Crisis in Oregon
}

Judith A. Ramaley

\begin{abstract}
Universities are being asked to prepare our students to navigate successfully in a complex and interconnected world and to contribute to the solution of difficult problems at work and in the communities where they live. Our universities must do the same. We must adapt our approaches to education, scholarship and community involvement in order to play a meaningful role in addressing the increasingly complex and wicked problems that our communities face. The housing crisis in Portland, Oregon offers an especially important example of a wicked problem that has developed slowly, will be very costly to resolve and involves a lot of uncertainty due to unpredictable social, economic and environmental factors. In 2015, policymakers in communities throughout Oregon began talking about a housing crisis as people searching for affordable housing found themselves competing with both the growing popularity of Oregon as a place to live and a real estate investment boom. Rents rose at a rate of $\$ 100 /$ month and over 24,000 units were needed to meet the demand in 2015. The problem remains acute in 2016. This article uses community efforts to understand and address the housing crisis as a focus to explore the changing roles of the university in participating in and contributing to these new social networks, multi-stakeholder initiatives and collaborations.
\end{abstract}

\section{Keywords}

Wicked problems, social networks, collaborations, university/community engagement

\section{The Changing nature of university/community engagement}

Universities and colleges have long been seen as important contributors to the public good both through their preparation of an educated citizenry and through their role as a source of knowledge that can be applied to the analysis and management of societal problems. The way that universities were educating their students and addressing community problems has changed significantly since the late $20^{\text {th }}$ century. Communities now face a confluence of factors that increase the complexity of the problems they must address. (Davis et al., 2015, Ramaley, 2014a). When campuses first began to embrace their public mission, service was approached as the identification of well-researched answers to clearly articulated problems. Such solutions work best when: (a) technical expertise is needed; (b) the consequences of actions are predictable; (c) the conditions are know in advance and well described; and (d) a central authority is in a position to ensure that appropriate actions are taken (Heifetz et al., 2009; Kania \& Kramer, 2013). In sum, the question is clear, there is little if any dispute about what has caused the problem and there is available expertise to propose a technical solution that can be applied to the problem. This approach informed the outreach and extension model as it developed in the $19^{\text {th }}$ century to offer expert solutions to common problems. We still have some of those kinds of problems, and the 
extension service still offers valuable service to both urban and rural communities. However, as the $21^{\text {st }}$ century has unfolded, we are facing more complex problems that require a very different approach. As Kania and Kramer (2013) point out, "predetermined solutions rarely work under conditions of complexity - conditions that apply to most major social problems - when the unpredictable interactions of multiple players determine the outcome." What we require now is both a different model of social progress and new ways to learn and work together. To work in this manner, communities must develop new approaches to collaboration and each participant must adapt its structure, its working relationships and its capacities to contribute to adaptive or emergent solutions to complex and wicked problems.

It is convenient to start the story of the changing interpretation of both the role of higher education, and its contributions to the public good, with Scholarship Reconsidered. Since 1990, we have witnessed significant changes in the ways in which the functions of research, teaching, and service have changed. At a watershed moment, the Kellogg Commission on the Future of State and Land-grant Universities (1999) redefined these three classical components of the university mission, to reflect changes that were taking place in our understanding of what it means to be educated for a new era, and how universities can interpret and enact their public mission. The terms became discovery, learning and engagement. Over the past few years, engagement has gradually been seen, not as a separate function, but as an approach to discovery and learning. The context in which these scholarly activities play out has expanded to include interactions between colleges and universities and the broader society. The world has become a living laboratory and classroom for scholarship and learning. All of this has taken place as a response to the growing number of complex and wicked problems that our institutions and our communities face in today's world. These kinds of problems require new ways of working together and new interpretations of the scholarly functions of discovery, integration,

interpretation and application (Boyer, 1990). Each of these aspects of scholarship and learning is changing in response to the realities of making sense of an increasingly complex world. However, the process has been slow, as both campuses and other sectors of society come to terms with the need for a new model of collaboration (Kezar \& Lester, 2009).

\section{Changes in the nature of engagement}

Ernest Boyer's concerns about undergraduate education were shaped by the challenges of the late 1980s and early 1990s. In its early forms, involvement with the community was viewed as a form of service, and as a way to prepare students for their responsibilities as citizens. A small group of college presidents formed Campus Compact to encourage students to participate in community volunteer work. Starting with a focus on community service and civic responsibility, the organization has grown to over 1100 member institutions committed to the public purposes of higher education and "dedicated solely to campus-based civic engagement, Campus Compact enables campuses to develop students' citizenship skills and forge effective community partnerships. Our resources support faculty and staff as they pursue community-based teaching and scholarship in the service of positive change (Campus Compact, 2016)."

Over the past thirty years since Campus Compact was formed, approaches to civic engagement and community engagement more broadly have continued to develop. It soon became clear that students who volunteered came back to their classes and to their campus experiences with 
unanswered questions. This led to the development of new pedagogies that linked community experiences to the curriculum. There is now an abundant literature on different approaches to experiential learning, including service-learning, community-based learning and problem-based learning. All of these "combine learning goals and community service [and impact] in ways that can enhance both student growth and the common good... and integrates meaningful community service with instruction and reflection to enrich the learning experience, teach civic responsibility, and strengthen communities (Campus Compact, 2016).”

As participation in experiential learning and community-based learning of various kinds began to grow, campuses found it necessary to design and implement support structures, to help faculty members and students identify and work effectively with community partners and to capture the growing volume of work and its impact on both student learning and on the community partners. Promotion and tenure policies and practices began to address these new forms of scholarly activity within the context of the disciplines and avenues for publishing reflections on this form of teaching and learning, and the results of engaged scholarship expanded.

The experiences of faculty and students in service-learning environments opened up a new set of scholarly questions, many of which addressed what are now often called wicked problems that require collaboration within the campus community and between the campus and the larger community. Over the past several years, both communities and campuses have begun to experiment with new approaches to understanding the changing context of life in the $21^{\text {st }}$ century, creating ways to bring the assets of a community together in new ways to build the capacity to explore and then respond to these kinds of problems and to promote new forms of learning and the capacity to put that learning to good use. The participation of higher education to these new collaborations and networks is changing as well.

These recent efforts generally involve college and university support but they are a far cry from the models of service to the community that the academy embraced prior to the mid-1990s. Universities are now learning to draw upon all aspects of Boyer's (Boyer, 1990) conception of Scholarship Reconsidered, including the integration and application of knowledge. These components of a full scholarly agenda are now coming into their own as forms of engaged scholarship in which community members work with faculty and staff to explore the context in which change is needed and the community itself identifies the most meaningful issues that should be addressed. What is then set in motion is a continuous cycle of exploration, innovation and learning that is pursued over a longer time period of time than the one offered by the constraints of an academic calendar and held together by a number of strategies that create a chain of continuous work. (Beaudoin \& Sherman, 2016). Working in this collaborative mode sets up a pattern of trial and error in which the participants learn to see problems in new ways and to apply emergent solutions in a complex environment where no proven solutions exist, the consequences of any actions taken are inherently unpredictable, and no single organization or individual is in control. (Kania \& Kramer, 2013). The term emergence is used to describe conditions that arise in unpredictable complex settings, where everything is connected in some way to everything else, and where perturbations can shift the dynamics of a situation in unpredictable ways (Arbesman, 2016).

\section{Dealing with a World of Wicked Problems}


Colleges and universities often reflect the social, cultural, economic and technological context in which they were founded. They often have difficulty in adapting to a changing world order that may call upon the academy to think and act differently. In a recent article, Danah Boyd (2016) pondered the question of why social science risks irrelevance. Boyd's arguments could apply just as easily to why our higher education institutions themselves risk becoming more and more out of step with the realities of life in the $21^{\text {st }}$ century. Boyd offers some advice that can frame our approach to thinking about the role of the Academy in today's world of complex problems and the importance of approaching scholarship and learning in new ways in order to foster the changes that will be necessary if we are to respond to a changing world.

Boyd (2016, p. B4) argues that "if we really want to matter, we need to think critically about the questions we ask - and the questions we don't ask — and what influences that distinction." Boyd goes on to say that "we need to find better ways of collectively identifying hard and important questions to ask, arenas of under-interrogated issues, and knowledge that the public needs."

How can we ask questions that matter, not only to us but also to our students and to the public? Again, Boyd has an answer (p. B5), If we are to make a difference and have an impact on the ability of our communities to identify and address their most challenging problems, we must be "deeply embedded within the social world that we seek to understand" and embrace the role that we can uniquely play "to inform and empower through knowledge." To support this, universities need to rethink not only the questions we ask but also how we are structured and what behaviors and results we honor and support. Our goal in this paper is to talk about what this means in the daily life of a campus community and what we already know about how to create new ways to approach learning and discovery through new working relationships both within our academic community and with our neighbors and colleagues within the communities we serve.

Wicked problems can be described in a number of ways. According to Camillus (2008) who drew upon earlier work by Rittel and Weber (1973), these kinds of problems (1) involve a range of stakeholders who have different values and priorities, (2) have origins in a tangled set of interacting causes, (3) are hard to come to grips with or make sense of, (4) continue to change as we seek to manage them and (5) have no clear or familiar solutions. These problems unfold in "a diverse and mutually interacting ecology" (Fung, 2015, p. 514) of people and organizations. Thus they require a great deal of boundary crossing to bring together ideas and resources from multiple sources. To capture the experiences of a diverse community, and to tap resources that otherwise might be ignored, new forms of interaction amongst citizens, government agencies, nonprofit organizations, and the business community are being created to support new approaches to community development (Fung, 2015, p. 515).

As Fung (2015, p. 517) explains, complex and wicked problems require "multi-sectoral problemsolving" and ways to remove the barriers to "pooling knowledge and coordinating action" through the formation of networks that connect organizations together. These networks are built on the basic concept that the solutions to many of society's most pressing problems today will require tapping into the expertise and ideas of different parts of the community and different disciplines. Solutions to multi-faceted problems must be designed in an adaptive way rather than chosen from a repertoire of well-researched and well tested technical solutions (Heifetz, et al., 2009). 


\section{New Approaches to Collaboration}

Kania and Kramer (2011) launched a new generation of thinking about collective efforts directed at complex problems in their series of articles on the concept and practice of collective impact. The components that characterize an effective collective impact model built up through networks of interaction amongst the participants in solution finding and action are: (a) a common agenda arrived at through a thoughtful process of exploration and interaction; (b) shared measurement systems and a willingness to look honestly at the evidence collected; (c) mutually reinforcing activities that draw on the strengths and interests of each participant; (d) continuous communication amongst the participants; and (e) a mechanism for backbone support that facilitates the building and maintenance of the relationships needed and the capacity of all participants to act knowledgably and in cooperation with the others.

The concept of boundary spanning has emerged to describe how ideas, information and influence can flow through a community, whether internal to a campus or external. The people who can facilitate this exchange and integration are often called boundary spanners. While the patterns of these interactions can vary considerably from one place to another, this interactivity carries a number of challenges for institutional leadership, and for the design and operation of its programs (Kezar \& Lester, 2009). Ernst and Chrobot-Mason (2011, p. xv) describe this pattern as follows:

In the traditional hierarchy of modern organizations, information flows vertically up and down the chain of command in a controlled way. Groups are differentiated and bounded. Organized by location or functions, group members have a high degree of similarity...we have learned how to coordinate work with those above and below us. We know what to expect from people in particular functions, locations or positions. Technological, geopolitical, and social transformations, however, have introduced many additional ways that information can flow-laterally, diagonally and in spirals - disrupting organizations by creating new communication channels, changing long-standing practices and diffusing the distribution of power based on "who knows what."

In short, our institutions are turning into complex social systems. We now must deal with ambiguity and imperfection and the uncertainty that comes from the way that the elements of a complex system interact with each other (Arbesman, 2016, p.7). Consider the difference between something that is complicated and something that is complex. As Arbesman (2016 p. 15) explains it, for a system to be complex, it is not sufficient for it to contain lots of parts. As he puts it, "The parts themselves need to be connected and interacting together in a tumultuous dance. When this happens, small changes cascade through this network, feedback occurs" and it matters what condition the system was in when the change began. A system like this is not predictable in its responses to various inputs or changes.

Colleges and universities are beginning to adapt to a complex world of wicked problems. Twentieth century institutions earned prestige from the work of individual faculty members and from the accomplishments of individual graduates. Increasingly, institutions are adopting a different approach that draws upon collaboration, and new forms of interaction within the campus community, and between the campus and the surrounding larger society. The goal is to create the capacity to work on problems that behave as complex systems. These problems are 
often called "wicked problems" and they require new patterns of communication, information flow, new ways to work together and new organizational designs and leadership practices (Ramaley, 2014a, 2014b). As colleges and universities begin to rethink their curriculum, their organizational structure, the roles and responsibilities of leadership and the values that will shape the way they assess the impact of their efforts, the communities with which they also must interact with are doing the same thing (Ramaley, 2016a, 2016b). In this new environment, "each expert knows a piece of the puzzle, but the big picture is too big to comprehend (Arbesman, 2016, p. 23). If we are to make sense of the complex problems that we face as a community, as a society and as a global network of people concerned about the future, we must learn to depend upon each other in new ways. This requires us to coordinate and blend our knowledge, our resources and our influence to create the capacity to address problems that are shaped by many interacting variables and that change shape as we seek to understand and manage them.

Individually, none of us can make sense of the complexities we face. Arbesman (2016 p. 92) points out that there are two ways to rethink how we develop and use expertise in a world of complexity. One solution is to work toward multidisciplinary approaches, in which we learn enough about each other's disciplines to be able to blend the insights from different fields, and apply multiple frameworks to the study of an issue or wicked problem. Another way is to move back toward the concept of a generalist or polymath (Arbesman, p. 142), who can connect one area of knowledge to another. These people can both see the larger picture and also can focus on the smaller details of a system. While the body of knowledge that a generalist or boundary spanner must traverse is now daunting, we are developing new ways to enable this kind of thinking, by preparing people who have deep expertise in one area or field but breadth of knowledge as well.

The National Science Foundation built boundary spanning into the Integrative Graduate Education and Research Traineeship (IGERT) program that ran from 1998 to 2015. Program officers and grantees often referred to the graduates of IGERT as T-shaped individuals. The stem of the $\mathrm{T}$ represents deeper knowledge of a field and the cross bar represents the capacity to integrate that deeper knowledge with a broader context. Although the IGERT program ended in 2015, this interdisciplinary program created an approach to an interdisciplinary graduate education that linked together science, technology, engineering, mathematics and the social sciences to create a new kind of boundary spanner or generalist capable of working with others to study and develop responses to wicked problems. These individuals can translate from one field to another and help specialists work together in new ways.

\section{Leading in a complex environment}

As Ernst and Chrobot (2011, p. xvi) point out, "the leadership advantage now goes to the people who are most closely linked to others and can work with a great variety of people from differing positions, backgrounds and locations." Such people create and operate within what Ernst and Chrobot call a "Nexus Effect," or a node within a complex interwoven set of working relationships and perspectives. They bridge the gaps created by traditional organization charts and individual departments and support units. They see those boundaries not as limits but as places of opportunity to create new capacity to work in a world of complexity.

In a complex environment, leadership must be distributed so that connections can form as needed and then dissolve and connect in new ways as work progresses or as a problem continues to 
develop new facets and interacting elements. In addition, leadership can no longer be thought of as the actions of individuals. Today, "the performance of an organization depends in part on the level of cooperation and coordination among interdependent leaders (Yukl, 2012, p. 78).

Yukl (2012, p. 68) contrasts three forms of leadership: task-oriented, relations-oriented and change-oriented. Task-oriented leadership focuses on achieving some primary objective in an efficient and reliable way. Relations-oriented leadership is directed at creating more human capital. Change leadership creates the capacity of a campus community to work in new ways to address complex problems that require collaborative learning and new ways of thinking and action. Unfortunately, most higher education institutions have been slow to embrace approaches to leadership that rely on collaboration and interdependence. These campuses are falling behind in the push to create the capacity to deal with complex and wicked problems, both on campus and beyond. Campuses that become adept at boundary spanning, both internally and within the broader community, are regaining their historic role as contributors to the public good, while finding new ways to educate their students for life and work in a complex world.

\section{Boundary Spanning in an Increasingly Uncertain Environment: The Portland State Experience}

Charles McClintock (2001, p. 349) foreshadowed today's leadership challenges by articulating two major issues facing higher education at the turn of the $21^{\text {st }}$ century. The first challenge is to link the contrasting and intersecting worlds of research and professional practice in order to prepare students to become effective problem-solvers. To make this possible, the second challenge is focus on "ways of relating academic specializations within the campus and across the campus-community boundary in response to needs for knowledge that transcends disciplinary boundaries." Both tasks depend upon rethinking organizational structures and leadership practices.

Institutions have experimented with different forms of bridges and nodes of interaction within the fabric of their campus culture and structure. In the past, these Centers and Institutes, as well as interdisciplinary efforts or special projects, often have become isolated, and have failed to influence the larger campus community of which they are a discrete part (Levine 1980). In retrospect, this can be understood by considering the larger adaptations that are needed if these new forms of scholarly and educational activity are to thrive. It has proven to be a challenge to move from an organizational design based on individual achievement and a largely vertical pattern (often described as a "chain of command") to a model in which more of the work is done by teams or collaborative interaction. Fortunately, new approaches to understanding organizational behavior and new approaches to leadership are emerging, whichare beginning to link previously separate components of an academic community in new and more creative ways.

At Portland State University, the Institute for Sustainable Solutions (ISS) through its Sustainable Neighborhoods Initiative (SNI) has begun to experiment with new forms of interaction with some of the neighborhoods in Portland (Beaudoin \& Sherman, 2016). These programs operate as a nexus effect (Ernst \& Chrobot, 2011) or node within the complex environment of Portland State while connecting in a number of ways deeply into the surrounding Greater Portland Region. The result is a boundary spanning model that can produce sustainable outcomes over time. Key to this approach is the concept of solutions-oriented learning in which student learning and development "is balanced with the goal of producing products and processes that can have a 
lasting effect for the project partner (Wiek et al., 2015, quoted in Beaudoin \& Sherman, 2016, p. 153)." To accomplish this, SNI weaves together a number of different student experiences over time, to maintain continuity in the university/community collaboration, including communitybased learning courses, internships, student research, and faculty involvement. Research also plays a core role in contributing to the capacity to address complex community problems. The goal of this approach to scholarship is to produce "actionable knowledge" or in Boyer's terms, application. These broader conceptions of learning and scholarship are demanding. They require a flexible and responsive infrastructure in order to be sustained over time. That support structure is provided by the Institute for Sustainable Solutions. As Beaudoin and Sherman explain, "Admittedly, transformative sustainability research and solutions-oriented learning are not easy... and are often more complex to design and implement." To make this approach work, a university must adapt its existing infrastructure, and its approaches to discovery and learning, to support long-term and thriving partnerships, both internal and external.

ISS functions as a boundary spanning entity although it is located within the fabric of Portland State University. Its role is to build a supportive ecosystem of people and ideas, both within the university and across the community, which can sustain a long-term collaboration and adapt as the interests, experiences and needs of the community develop, and as the wicked problem that is the target of the collaboration evolves in response to whatever interventions are undertaken.

ISS has developed a core set of functions and capacities that can support long-term interactions within the community and within the university as well. The process starts with facilitating conversations with community members to identify a focus for a collaborative project that will address an important community issue. This is amplified by attention to storytelling to grow broader awareness and interest in the project that the community has chosen through its own deliberative process. ISS then serves as a project manager ensure that everyone remains focused on the project outcomes and that there is consistent and strong community involvement. ISS also functions as a neutral party to help resolve any conflicts that arise. Throughout the project, ISS provides support for leveraging new resources to expand and deepen the impact of a particular project or program, provide ongoing assessment and opportunities for reflection and adjustments as the project unfolds and the participants learn more and create a bridge from one part of a longterm effort to the next stage by creating the capacity to reflect on each phase of a project and plan for the next. To make all of this work, ISS provides program managers, who are familiar with the neighborhoods, communication specialists, development personnel assessment staff and researchers. All of these different aspects and roles are held together by careful efforts to facilitate the interactions amongst the participants.

Another experiment with collaboration involves a shift from the more traditional think tank model for analyzing problems to an Oregon Idea Lab concept that focuses on exploring and designing collaborative responses to pressing Oregon problems. Still under development, the Idea Lab concept draws upon all of the facets of the Boyer model of scholarship. It relies upon concepts of engaged scholarship and learning to produce "solutions-oriented learning" and "actionable knowledge" through a process that draws on the expertise of scholars, practitioners and community members. It relies on the capacity of a particular community to identify and then act collaboratively to address an important problem.

The kinds of problems that the Idea Lab concept is designed to address require a long-term strategy, involve both uncertainty and risk, require input from multiple perspectives, depend 
upon effective boundary spanning in order to bring together the people and resources needed and will demand significant investment of time and financial resources. To make this work, it will be ne3cessary to reconsider some public sector priorities, reorganize scarce resources and create new ways to work and learn together. These efforts will require some new approaches to pooling resources for shared purposes and new ways to monitor and measure progress in ways that make sense to a diverse group of participants. In this model, the university role also shifts from defining problems to promoting new working relationships and dialogue, providing research findings that can shed light on a problem and creating new approaches to building a package of different learning models and student and faculty opportunities guided by the interests of the community and chosen to provide mutual benefit to university participants and community members. The mission of an Idea Lab will be to incubate, investigate, collaborate with community partners to implement solutions and then study and communicate practice-informed ideas and approaches for enhancing the future of Oregon - all of this in cooperation with community leaders and citizens.

\section{The Housing Crisis in Portland}

The housing crisis in Portland, Oregon offers an especially important example of a wicked problem that has developed slowly, will be very costly to resolve, and involves a lot of uncertainty, due to unpredictable social, economic and environmental factors.

The stage was set for a collaborative effort earlier when the Meyer Memorial Trust launched an affordable housing initiative in 2007 that was focused on preserving and increasing Oregon's stock of affordable housing while helping low income renters to achieve stability and selfsufficiency. The Oregon-based Foundation awarded \$8.8. million in grants to 17 nonprofits, with the goal of preserving up to 6,000 units of federally rent-subsidized housing, build the capacity of nonprofits in rural areas to increase the quality and quantity of housing outside the Portland metro area and provide better resident services to help low-income renters achieve stability and self-sufficiency. An assessment of that project was prepared and issued in April 2013 (Smock 2013). In 2015, Meyer Memorial Trust "recommitted to the Initiative, pledging another $\$ 11$ million over the next five years to support affordable housing solutions from Oregon's wild, windy coastline to its austere eastern landscape of deserts and mountains."

In 2011, the Portland Housing Bureau issued its 2011-2013 strategic plan and set ambitious goals to provide more housing for low income renters and working with its partners throughout the region to assess the city's housing needs and to choose the best solutions to efficiently meet those needs while working out how to pay for those solutions.

In 2015, policymakers in communities throughout Oregon began talking about a housing crisis as people searching for affordable housing found themselves competing with both the growing popularity of Oregon as a place to live and a real estate investment boom. Rents rose at a rate of $\$ 100 /$ month and over 24,000 units were needed to meet the demand in 2015 . The problem remains acute in 2016. In 2015, the Portland City Council declared a "housing emergency" and increased funding for affordable housing, specifically in the city's urban renewal areas and added $\$ 64$ million to the city's affordable housing budget to be spent over the following decade funded by a property tax set-aside. The Council also directed the Housing Bureau to find a new source of funding that could be used city-wide. 
In response to this new attention on issues of housing affordability and homelessness, the City Club of Portland convened a research committee to look at housing affordability in Portland. The committee issued its report in June 2016. So far, the crisis continues to intensify, and there is, as yet, no coordinated approach to dealing with the issues on a citywide or regional basis. As this article is being written, a coalition of businesses and advocates for the homeless are supporting a measure on the November Oregon Ballot that would generate \$258 million over twenty years to build or renovate 1300 rental units, 600 of which would be set aside for individuals whose income is lower than $30 \%$ of the median family income in our area.

So, what is the university doing to build capacity to deal with the imbalance between the available housing options and the needs and interests of the people seeking a place to live?

\section{Gentrification in Living Cully}

Cully is a neighborhood in Portland. Unlike many other neighborhoods, the community has developed a strong network of non-profits, government agencies, small businesses and neighborhood groups that work together to address issues that affect people who live there. Cully was one of the first neighborhoods to join the Sustainable Neighborhoods Initiative but showed considerable reluctance to trust the motives of the university. It also assumed that as a public institution, Portland State was obligated to bring resources to the community in the form of money. Now, two years later, those reservations have been resolved and Cully offers a good example of the process by which people in a community can choose a signature project and work together with support from the university to address the issue, in this case the problem of displacement of people of modest income due to the gradual gentrification of the Cully neighborhood.

Several university undergraduate classes explored policies that have been adopted in other places to address the problem of gentrification and displacement. A paid graduate internship provided project management to coordinate the project and provide continuity from one class to another. The focus was to explore the possibility of acquiring land for affordable housing projects by adapting the land trust model to the conditions in Cully. The first class gathered examples of the use of land trusts in a number of cities. The next class looked at the case studies prepared by the first class. A paid intern then adapted the lessons derived from the studies by the two undergraduate classes to the needs and conditions in Cully, and assisted the Living Cully Coalition in preparing proposals to the City of Portland for ways to counteract the displacements being driven by gentrification. With help from SNI, the community has developed a new comprehensive plan that includes land banking. The City of Portland is considering putting some funding into enactment of the plan.

\section{Creating a community voice in Lenz}

Lenz is another community in the Portland region but unlike Cully, Lenz does not have an effective community coalition or network to identify signature projects to help the area and to build a shared vision of what the people who live there want and need. Working with four organizations that have an interest in the Lenz neighborhood, SNI is helping to build capacity to draw upon the experiences and concerns of the people who live there, in order to create one or more themes around which the community can rally. The motivation for this came from two PSU students who had worked on a project in Lenz as the focus for their capstone project in PSU's 
general education program, called University Studies. SNI advised and supported the students who developed several scenarios as a vehicle for bringing the community together to imagine a better future for the neighborhood. The focus is not on the university and its interests but on the neighborhood and its challenges. The overall goal to promote the ability of people there to identify, explore and work together on issues that are important to life in that part of Portland.

Both approaches enact the university commitment of Let Knowledge Serve the City, but in one case, the knowledge is produced as a collaboration between Portland State and people in the community, and in the other case Portland State simply helps create the opportunity for the community to tap into its own knowledge. As a theme emerges that captures the imagination of the people in Lenz, the university will move into its supportive role that integrates a succession of projects focused on that signature theme and that sets up a pattern where each part draws on the results of the project that preceded it.

\section{Age-friendly Housing and the Challenge of Citizen Participation in Decision-making}

The Institute on Aging at Portland State University has convened a cross-section of individuals including representatives from city agencies, disability services, housing advocates, metro area economists, AARP Oregon, and groups such as the Oregon Opportunity Network, which focus on age-friendly housing and what efforts are currently underway to provide a range of housing options for older adults and to address the housing crisis in Oregon. While this mix of people all have a stake in addressing Portland's housing crisis, they play very different roles, see the problems through different perspectives, and have very different opinions about the nature of the problem to be addressed. Some equate aging and disability and focus on services for the elderly, including age-friendly housing options that will allow the elderly to age in place. Others are more focused on intergenerational living arrangements that create opportunities for the generations to support each other. A few are focused on the interests of empty-nesters who are looking for well-designed options as they down-size. Affordability is a theme that unites these people, but each has a different idea about what affordability means, what housing choices are important, and how to deal with the shortage of affordable options.

In convening this group of housing advocates, the Institute on Aging hopes to create a new kind of advocacy coalition (Sabatier, 1988) that can build upon the knowledge and interests of a wide range of participants (Neal et al., 2014). One focus of this effort is the Residential Infill Project organized by the Portland Bureau of Planning and Sustainability this year. The goal is to plan for the estimated 123,000 new households that will arrive in Portland by 2035. Although the task group solicited input from the community, only current homeowners showed up to discuss the issues. The committee was composed of developers, designers, neighborhood-based advocates and other community members. Once the group had prepared a preliminary report, the task was to gather widespread community input.

One challenge for that project has been to include the needs of older and disabled adults. The Institute on Aging developed a way to solicit input from this population, most of whom are usually silent on these important issues but deeply affected by policy choices and investment strategies made by the City of Portland and by developers. In July 2016, Portland State hosted an open house to gather input on the Residential Infill Project policy proposals from older adults, people with disabilities and advocates for accessible as well as affordable housing (DeLaTorre, 2016). Extra care was taken to ensure that the meeting was equitable and inclusive both through 
how invitations were issued and by making the assistive strategies available during the meeting including American Sign Language Interpreters and real-time captioning. This example illustrates how much care must be devoted to ensuring that the people living in a community have a voice in shaping decisions that will affect them directly.

\section{Conclusion}

The problems facing our communities and our nation today have become steadily more complex with more and more stakeholders and less and less agreement about why our problems exist and what we can do to manage them. At the same time, we appear to be losing our capacity for informed and thoughtful discussion of these issues and less able to engage in the public problemsolving that can generate effective options for addressing them. There is an urgent need to create opportunities to build trust and to engage in constructive conversations about what lies ahead and hop to generate better outcomes. In this context, colleges and universities are uniquely positioned to play a key role in building community capacity to identify and explore pressing problems and to provide support for community organizations and advocacy groups to work together to build healthier communities. Many universities are creating fresh interpretations of the traditional roles and responsibilities of our campuses. We are building the capacity to learn in new ways, to draw upon the complex ecosystem of people and knowledge that makes up our campus community and to work in effective ways with the communities to educate our students and prepare them for life and work in the $21^{\text {st }}$ century. We are learning how to support the new forms of collaboration and the social networks that are forming within community settings by facilitating and supporting collaboration rather than by designing or directing it (Critchley, 2015). New neighborhood-based approaches to addressing the housing crisis in the Portland area and the development of new networks that bring together representatives from each sector of society are examples of ways that universities are adapting their approach to discovery and learning in order to interact in new ways with other organizations and with the people who live in the communities from which we draw inspiration and ideas.

\section{References}

Arbesman, S. (2016). Overcomplicated. Technology at the Limits of Comprehension. New York: Current.

Bandy, J. (2016). Vanderbilt university: Center for teaching. Retrieved from https://cft.vanderbilt.edu/guides-sub-pages/teaching-through-community-engagement/

Beaudoin, F. D. \& Sherman, J.D.B. (2016). Higher education as a driver for urban sustainability outcomes: The Role of Portland State University Institute for Sustainable Solutions. In B.D. Worthman-Galvin, J. H. Allen and J. D.B. Sherman (Eds.), Let Knowledge Serve the City (pp. 152-172). Sheffield UK: Greenleaf Publishers.

Boyer, E. L. (1990). Scholarship Reconsidered Priorities of the Professoriate. Princeton, NJ: Ther Carnegie Foundation for the Advancement of Teaching. 146 pages. 
Boyd, D. (2016, August 5). Why Social Science Risks Irrelevance. The Chronicle Review, pp. B4-B5.

Campus Compact. (2016). Retrieved from http://compact.org/who-we-are/

Camillus, J. C. (2008 May). Strategy as a wicked problem. Harvard Business Review, 86(5), 99106.

Critchley, S. (2015). Does Your Backbone Organization Have Backbone? Stanford Social Innovation Review. Retrieved from https://ssir.org/articles/entry/does_your_backbone_organization_have_backbone

Davis, A. P., Dent, E. B., \& Wharff, D. M. (2015). A Conceptual Model of Systems Thinking Leadership in Community Colleges. Systemic Practice and Action Research, 28(4), 333-353. https://dx.doi.org/10.1007/s11213-015-9340-9

DeLaTorre, A. (2016). Residential infill project: Participant observation report. Portland State University, Institute on Aging. Retrieved from: http://agefriendlyportland.org/wpcontent/uploads/2016/10/DeLaTorre_Residential-Infill-Project-Report_Oct14.2016.pdf

Ernst, C. \& Chrobot-Mason, D. (2011). Boundary Spanning Leadership. New York: McGraw Hill Publication.

Fung, A. (2015). Putting the public back into governance: The challenges of citizen participation and its future. Public Administration Review, 75(4), 513-522. doi:10.1111/puar.12361.

Heifetz, R., Grashow, A., \& Linsky, M. (2009). The practice of adaptive leadership. Tools and tactics for changing your organization and the world. Boston: Harvard University Press.

Kania, J., \& Kramer, M. (2011, Winter). Collective impact. Stanford Social Innovation Review, $9(1), 3641$

Kania, J \& Kramer, M. (2013). Embracing Emergence: How Collective Impact Addresses Complexity. Stanford Social Innovation Review. https://ssir.org/articles/entry/embracing_emergence_how_collective_impact_addresses_complexi ty.

Kellogg Commission on the Future of State and Land-grant Universities. (1999). Returning to our roots: The engaged institution. Washington DC: National Association of State Universities and Land-Grant Colleges.

Kezar, A. J. and Lester, J. (2009). Organizing higher education for collaboration. A guide for campus leaders. San Francisco: Jossey Bass. 
Levine, A. (1980). Why innovation fails. Albany: SUNY University Press. Retrieved from https://books.google.com

McClintock, C. (2001). Spanning boundaries of knowledge and organization: Collaborations for mind and management in higher education. Organization, 8(2), 349-357.

https://dx.doi.org/10.1177/1350508401082018

Meyer Memorial Trust Affordable Housing Initiative (2016). Retrieved from http://mmt.org/ourportfolios/housing/ and http://mmt.org/2015/03/healthy-oregon-depends-on-affordable-housing/

Neal, M. B., DeLaTorre, A.K., \& Carder, P.C. (2014). Age-friendly Portland: A university-citycommunity partnership. Journal of Aging and Social Policy 26(1-2), 88-101.

http://dx.doi.org/10.1080.08959420.2014,854651

Ramaley, J.A. (2007). Reflections on the Public Purposes of Higher Education. Retrieved from http://www.winona.edu/president/Media/WingspreadArticle.pdf.

Ramaley, J. A. (2014a). The changing role of higher education: Learning to deal with wicked problems. Journal of Higher Outreach and Engagement, 18(3), 7-21.

Ramaley, J. A. (2014b). Education for a rapidly changing world. In H. C. Boyte (Ed.). Democracy's Education: A Symposium on Public Work, Citizenship, and the Future of Higher Education (pp. 91-98). Vanderbilt University Press.

Ramaley, J.A. (2016a). Collaboration in an Era of Change: New forms of Community ProblemSolving. Metropolitan Universities Journal, 27(1), 3-24. Retrieved from https://journals.iupui.edu/index.php,muj/issue/view/1223.

Ramaley, J.A. (2016b) Navigating the rapids: On the frontiers of the knowledge revolution. Liberal Education, 101(4), 36-43.

Rittel, H. W. J., \& Webber, M. M. (1973). Dilemmas in a general theory of planning. Policy Sciences, 4, 155-169. https://dx.doi.org/10.1007/BF01405730

Sabatier, P.A. (1988) An advocacy coalition framework of policy change and the role of policyoriented learning therein. Policy Sciences, 21, 129-168. https://doi.org/10.1007/BF00136406

Wiek, A.Xiong, A., Brundiers, K., \&Leeuw, S. (2015) Integrating problem-solving and projectbased learning into sustainability programs: A case study on the School of Sustainability at Arizona State University. International Journal of Sustainability and Higher Education, 14(4), 433-449.

Yukl, G. (2012) Effective leadership behavior: What we know and what questions need more attention. Academic of Management Perspectives, November 2012, 66-85.

https://dx.doi.org/10.5465/amp.2012.0088 


\section{Author Information}

Dr. Judith A. Ramaley is President Emerita and Distinguished Professor of Public Service at Portland State University in the Mark O. Hatfield School of Government. She has served as President of Winona State University (MN) and The University of Vermont. She is a Senior Scholar with the Association of American Colleges and Universities and has a special interest in the meaning and design of an undergraduate education, civic and community engagement and leadership of change in higher education. She served as Assistant Director of the Education and Human Resources (EHR) Directorate at the National Science Foundation from 2001-2005.

Judith A. Ramaley

Mark O. Hatfield School of Government

Portland State University

Post Office Box 751

Portland, Oregon 97207

Email: jramaley@pdx.edu

Telephone 703-623-8927 